\title{
Bacterial Vaginosis: The Quest Continues
}

Money continues to be spent on observational studies attempting to link bacterial vaginosis (BV) to preterm delivery. Despite considerable financial investment, the results are at best confusing. Two recent studies address whether using oral metronidazole to treat pregnant women with BV reduces the incidence of preterm delivery. A well-conceived study by McDonald et al. examined treatment not of an infection, but of a disturbance or alteration in the microflora of the vaginal ecosystem. ${ }^{1}$ This randomized placebo-controlled study found no difference in the incidence of preterm delivery between pregnant women with BV treated with oral metronidazole and pregnant women with untreated BV. The recent study by Carey and other members of the Maternal-Fetal Medicine Network also found that oral metronidazole did not have any significant effect on reducing the rate of preterm delivery, as well as no significant reduction in the rate of preterm labor, intra-amniotic infection, postpartum endometritis, neonatal sepsis, or admissions to the neonatal nursery. ${ }^{2}$ Earlier studies by Josef et al. and McGregor et al. also fail to demonstrate a positive effect on the incidence of preterm delivery after treating BV with intra-vaginal clindamycin. , $^{3,4}$

It appears to be premature to screen and treat all pregnant women for BV. Instead, there must be a concentrated effort to study the microbiology of the endogenous vaginal microflora by first developing an understanding of the interrelationships among the bacteria that inhabit the lower genital tract. Failure to understand the mechanisms controlling the equilibrium of a healthy vaginal ecosystem will only produce observational studies, which will continue to lead to recommendations for treatment of both pregnant and nonpregnant women diagnosed with BV. This results in a greater use of antibiotics, tested and untested, for treating BV.

Because currently available treatments for BV have not proven very successful, physicians have used other antibiotics in the hope that they will be more effective. This indiscriminate use of antibiotics will eventually lead to the selection of resistant strains within this ecosystem. Since current treatment studies have not produced long-term positive results, it may be that administering antibiotics with a spectrum of activity directed against mainly obligate anaerobic bacteria is not the correct approach. It is important to remember that $\mathrm{BV}$ is not an infection, but an alteration in the endogenous vaginal microflora apparently preceded by decreased growth of certain Lactobacillus species and increased growth of Gardnerella. Further, growth of Gardnerella and other bacteria leads to a vaginal environment that has decreased concentrations of both hydrogen ions and oxygen.

In addition to understanding the relationships between bacteria inhabiting the lower genital tract, we also need information about environmental factors that assist in controlling or favoring growth of one bacterium over another. Understanding synergistic and antagonistic mechanisms will facilitate an understanding of BV's contribution to physiology of a variety of pelvic infections in both pregnant and nonpregnant women. The time has come for a significant research effort into the microbiology, pathophysiology, and diagnosis of BV, and then into methods of re-establishing a healthy vaginal microflora. Observational studies must give way to scientific research.

\section{REFERENCES}

1. McDonald HM, O'Loughlin JA, Vigneswaran R, et al. Impact of metronidazole therapy on preterm birth in women with bacterial vaginosis flora (Gardnerella vaginalis): a randomized, placebo controlled trial. Br J Obstet Gynaecol 1997;104:1391-1397.

2. Carey JC, Klebanoff MA, Hauth JC, et al. Metronidazole to prevent delivery in pregnant women with asymptomatic bacterial vaginosis. N Engl J Med 2000;342:534-540.

3. Joesef MR, Hillier SL, Wiknjosastro G, et al. Intravaginal clindamycin treatment for bacterial vaginosis: effects on preterm delivery and low birth weight. Am J Obstet Gynecol 1995;173:15271531.

4. McGregor JA, French JI, Jones W, et al. Bacterial vaginosis is associated with prematurity and vaginal fluid mucinase and sialidase: results of a controlled trial of topical clindamycin cream. Am J Obstet Gynecol 1994;170:1048-1060. 


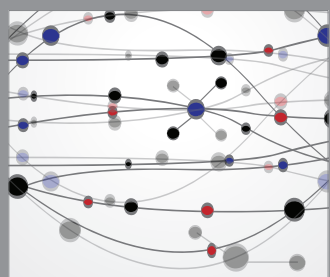

The Scientific World Journal
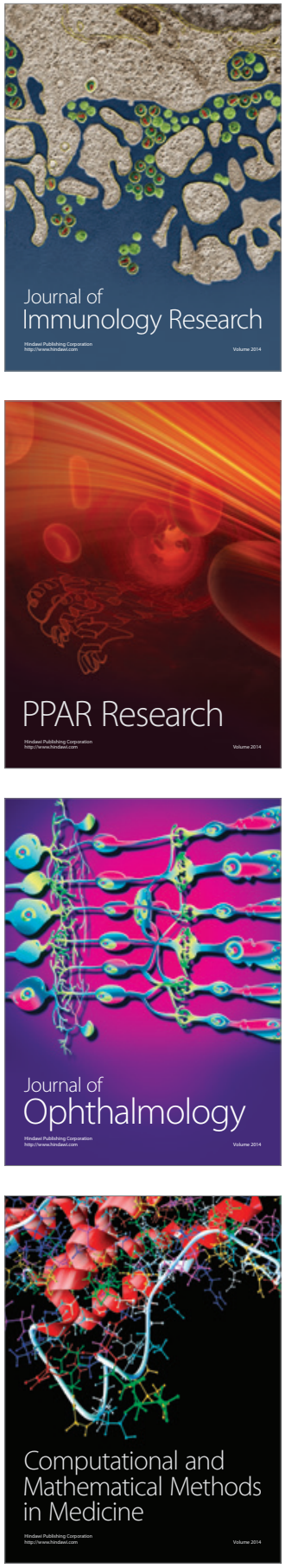

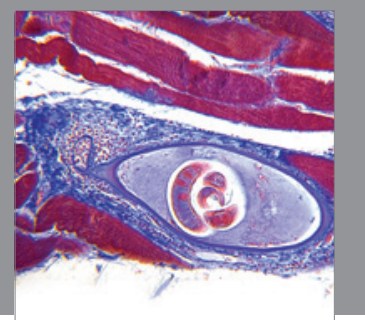

Gastroenterology

Research and Practice
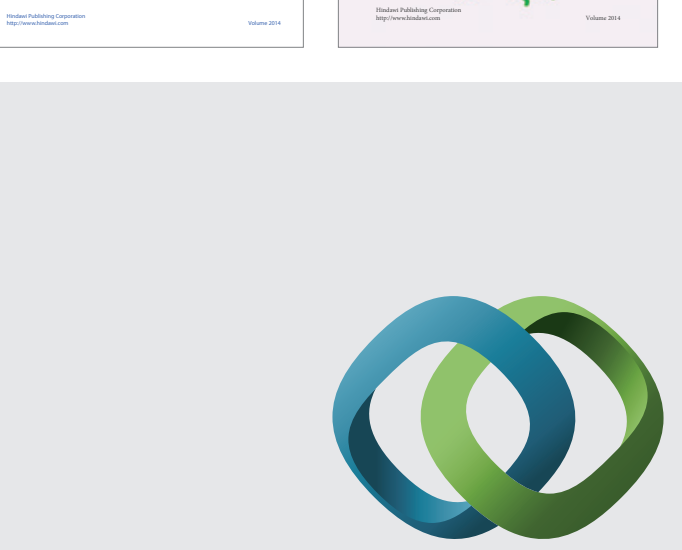

\section{Hindawi}

Submit your manuscripts at

http://www.hindawi.com
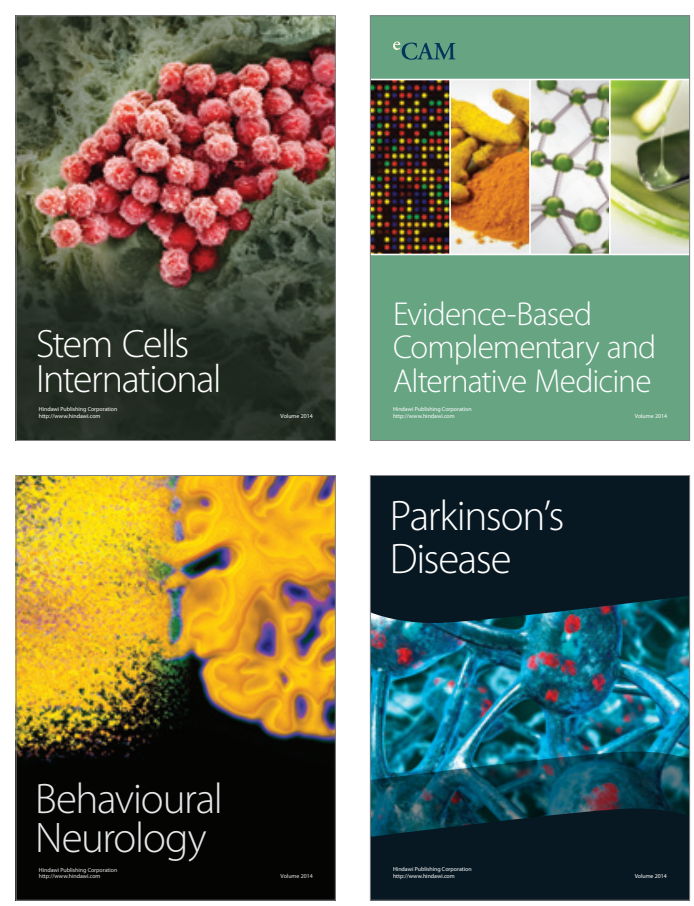

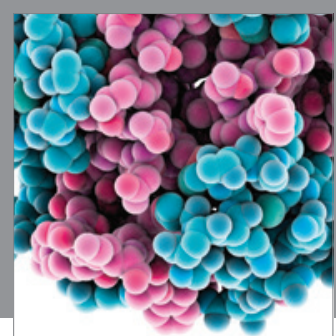

Journal of
Diabetes Research

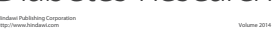

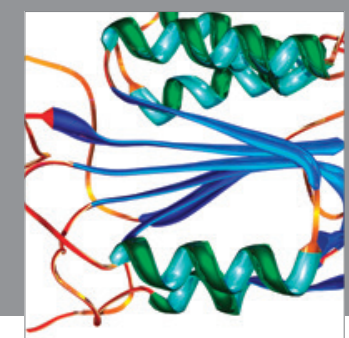

Disease Markers
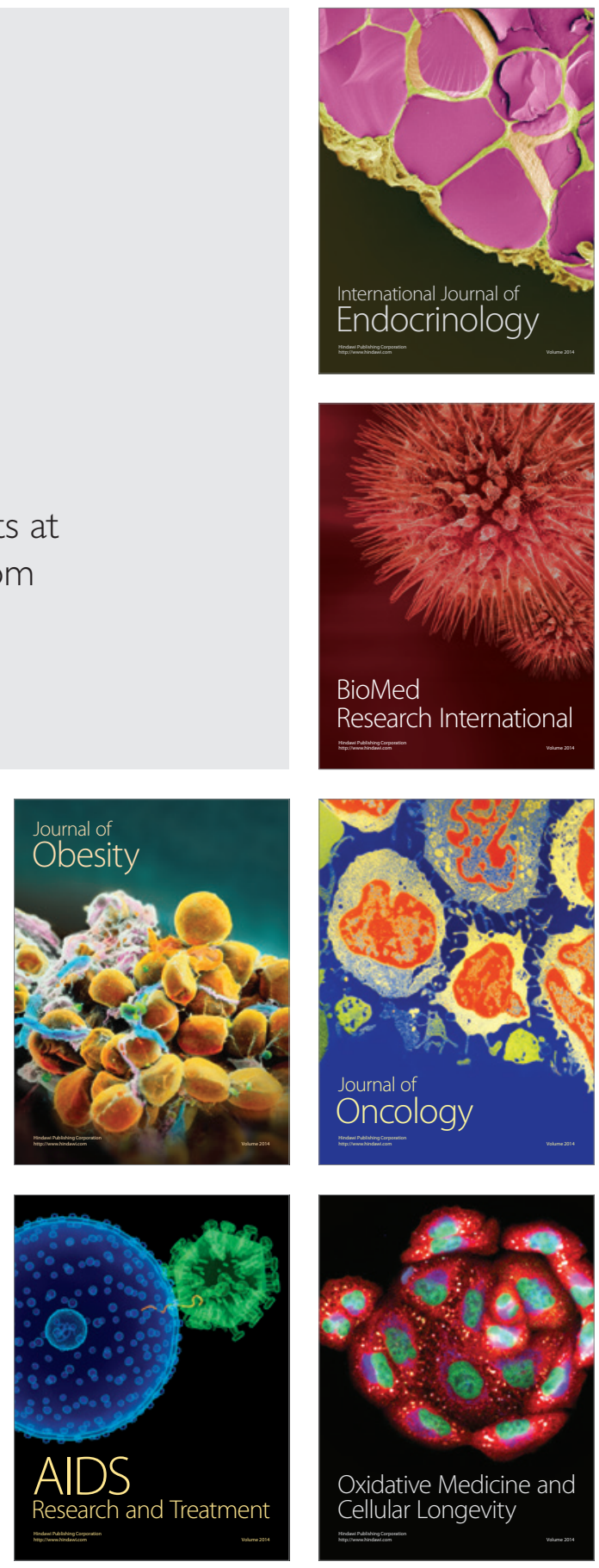